\title{
Structure and Properties of Barium Titanate Lead-Free Piezoceramic Manufactured by Binder Jetting Process
}

\author{
Vadim Sufiiarov*(D), Artem Kantyukov, Anatoliy Popovich and Anton Sotov \\ Institute of Mechanical Engineering, Materials, and Transport, Peter the Great St. Petersburg Polytechnic \\ University, 195251 Saint Petersburg, Russia; kantyukov.artem@mail.ru (A.K.); director@immet.spbstu.ru (A.P.); \\ SotovAnton@yandex.ru (A.S.) \\ * Correspondence: vadim.spbstu@yandex.ru
}

Citation: Sufiiarov, V.; Kantyukov,

A.; Popovich, A.; Sotov, A. Structure and Properties of Barium Titanate Lead-Free Piezoceramic

Manufactured by Binder Jetting

Process. Materials 2021, 14, 4419.

https://doi.org/10.3390/ma14164419

Academic Editor: Haim Abramovich

Received: 18 June 2021

Accepted: 4 August 2021

Published: 6 August 2021

Publisher's Note: MDPI stays neutral with regard to jurisdictional claims in published maps and institutional affiliations.

Copyright: (c) 2021 by the authors. Licensee MDPI, Basel, Switzerland. This article is an open access article distributed under the terms and conditions of the Creative Commons Attribution (CC BY) license (https:// creativecommons.org/licenses/by/ $4.0 /)$.

\begin{abstract}
This article presents the results of manufacturing samples from barium titanate $\left(\mathrm{BaTiO}_{3}\right)$ lead-free piezoceramics by using the binder jetting additive manufacturing process. An investigation of the manufacturing process steps for two initial powders with different particle size distributions was carried. The influence of the sintering and the particle size distribution of the starting materials on grain size and functional properties was evaluated. Samples from fine unimodal powder compared to coarse multimodal one have $3-4 \%$ higher relative density values, as well as a piezoelectric coefficient of 1.55 times higher values $\left(\mathrm{d}_{33}=183 \mathrm{pC} / \mathrm{N}\right.$ and $118 \mathrm{pC} / \mathrm{N}$ correspondingly). The influence of binder saturation on sintering modes was demonstrated. Binder jetting with $100 \%$ saturation for both powders enables printing samples without delamination and cracking. Sintering at $1400{ }^{\circ} \mathrm{C}$ with a dwell time of $6 \mathrm{~h}$ forms the highest density samples. The microstructure of sintered samples was characterized with scanning electron microscopy. The possibility of manufacturing parts from functional ceramics using additive manufacturing was demonstrated.
\end{abstract}

Keywords: additive manufacturing; binder jetting; lead-free piezoceramic; barium titanate; sintering; piezoelectric properties

\section{Introduction}

Functional ceramics are a class of materials that exhibit special properties in addition to those already inherent in ceramics, such as chemical and thermal stability. Functional ceramics typically exhibit one or more unique properties: biological, electrical, magnetic, or chemical. [1]. Due to this, they are used in engine production, aviation, and space industries [2]. The most promising types of functional ceramics include piezoceramics [3]. Piezoelectric ceramics are used to make sensor devices, energy harvesters, and actuators [4-6]. Piezoelectric materials are of particular interest as pressure and temperature sensors in high-frequency environments [7,8]. Piezoelectric ceramics have generated particular interest in the power industry because they can withstand the harsh environmental conditions present in energy conversion systems [9]. However, despite their advantages as sensitive devices, piezoceramics also have the same internal disadvantages that are observed in most ceramic materials: they are difficult to process [10], and their fragility causes low fracture resistance [11]. Therefore, the manufacture of non-standard complex geometries from ceramic materials can be practically impossible using conventional manufacturing methods. The proposed method for circumventing this problem is the manufacture of complex ceramic parts using additive manufacturing (AM) [12]. AM has such advantages as the absence of expensive tools, easy scalability of the process, the ability to implement parts of complex shapes, a high degree of material utilization and minimum production time [13]. One of the most relevant materials for ceramic additive manufacturing is a piezoelectric material since it generates an electric charge when deformed or, conversely, deforms when an electric potential is applied. The use of AM for the manufacture of piezoelectric materials will expand the scope of their application, expanding the 
possibilities of forming multilayer, as well as complex geometries of structures. Therefore, the possibility of integrating piezoelectric materials during the manufacturing process itself would lead to the creation of multifunctional structures within a single processing process. With great freedom in the achievable geometries of piezoelectric elements, the prospect opens for a significant improvement in the performance of many devices based on piezoelectric and ferroelectric properties [14,15].

Some previous investigations of additive manufacturing lead-based piezoceramics have been made using direct writing/FDM [16,17], stereolithography-based processes [18,19], and ink-jetting [20]. Due to the toxicity of lead compounds, the development of new piezomaterials and technologies is moving towards lead-free piezomaterials. Barium titanate $\left(\mathrm{BaTiO}_{3}\right)$ is one of the most widely used lead-free piezoceramic materials, which became widespread due to its high dielectric and piezoelectric properties [21]. The most promising methods of 3D printing $\mathrm{BaTiO}_{3}$ are direct writing (DW) [22-25], vat photopolymerization (VP) [26-30], and binder jetting (BJ) [31-34]. Samples printed using DW have the best piezoelectric coefficient values $\left(\mathrm{d}_{33}=200 \mathrm{pC} / \mathrm{N}\right.$ [22] $)$ and a density $\left(6.01 \mathrm{~g} / \mathrm{cm}^{3}\right.$ [23] $)$ close to the theoretical density limit of $\mathrm{BaTiO}_{3}\left(6.02 \mathrm{~g} / \mathrm{cm}^{3}\right)$. However, the quality of the surface printed layer is rather rough, which may be a limitation for using this technology. It is also worth noting that difficulties arise when using printing nozzles with a diameter less than 500 microns-the nozzle can clog with ceramic powder particles, and this reduces the accuracy of printing parts [23]. Samples printed using VP also have high piezoelectric coefficient values $\left(\mathrm{d}_{33}=165 \mathrm{pC} / \mathrm{N}\right.$ [27] and high material density $\left(5.64 \mathrm{~g} / \mathrm{cm}^{3}\right.$ [26]). However, there are next limitations when using this 3D printing technology [29]: (i) using 3D printer with a layer spreading system for viscous slurry with a high solid loading of ceramics in the photopolymer resin; (ii) the high refractive index of UV light for $\mathrm{BaTiO}_{3}$ that limits the curing depth; (iii) a long time of debinding process that directly affects the final result of the subsequent sintering. Samples printed using BJ have low piezoelectric coefficient values $\left(\mathrm{d}_{33}=74.1 \mathrm{pC} / \mathrm{N}\right.$ [31], $\mathrm{d}_{33}=112 \mathrm{pC} / \mathrm{N}$ [32] and have a low density $\left(3.93 \mathrm{~g} / \mathrm{cm}^{3}\right.$ [31], $2.21 \mathrm{~g} / \mathrm{cm}^{3}$ [32]). However, this technology ensures the high quality of printed parts and excludes difficulties of the debinding process.

The BJ additive process is a method where a nozzle print-head jets a liquid binder on a powder layer in places that correspond to the cross-section of the computer model of a part. The result of BJ printing is a green model with low mechanical properties and high porosity. The green model needs further curing, debinding, and sintering. As a result, the characteristics of parts made of the polymer [35], metal [36-38] and ceramics [39] printed on a $3 \mathrm{D}$ printer largely depend on manufacturing and postprocessing parameters. Consequently, the behavior of functional ceramics made with additive technologies must be further studied to expand the capabilities of this new technique.

In this paper, $\mathrm{BaTiO}_{3}$ lead-free piezoceramic was used to study the additive manufacturing of piezoelements by using the BJ process. The influence of the manufacturing process on the properties of the material was characterized and discussed, and the dielectric and piezoelectric properties of the manufactured samples were measured.

\section{Materials and Methods}

\subsection{Materials}

Two types of $\mathrm{BaTiO}_{3}$ powder were used for printing by BJ: (i) micron powder with multimodal particle size distribution (PSD) $\left(\mathrm{C}-\mathrm{BaTiO}_{3}, \mathrm{ZAO}\right.$ NPF Luminofor, Stavropol, Russia) $\mathrm{D}_{10}-0.1 \mu \mathrm{m}, \mathrm{D}_{50}-3.4 \mu \mathrm{m}, \mathrm{D}_{90}-25.4 \mu \mathrm{m}$, and (ii) submicron powder with unimodal PSD (F-BaTiO 3 , Acros Organics, Geel, Belgium) $\mathrm{D}_{10}-0.6 \mu \mathrm{m}, \mathrm{D}_{50}-1.1 \mu \mathrm{m}, \mathrm{D}_{90}-2.1 \mu \mathrm{m}$. Figures 1 and 2 shows images of as-received powders. The $\mathrm{C}-\mathrm{BaTiO}_{3}$ powder has particle sizes of about $1 \mu \mathrm{m}$, forms agglomerates up to $25 \mu \mathrm{m}$ (Figure 1). The $\mathrm{F}_{-} \mathrm{BaTiO}_{3}$, powder has particle sizes about $1 \mu \mathrm{m}$ (Figure 2). Figure 3 shows the particle size distributions which demonstrates that the $\mathrm{C}-\mathrm{BaTiO}_{3}$ powder consists of agglomerates and reveals three peaks and contains small particles. The unimodal powder is much more homogeneous, while in the case of the multimodal powder one can observe the agglomeration of small particles 
into larger clusters, which correspond to the third peak in the PSD with a medium size at about 20 microns.
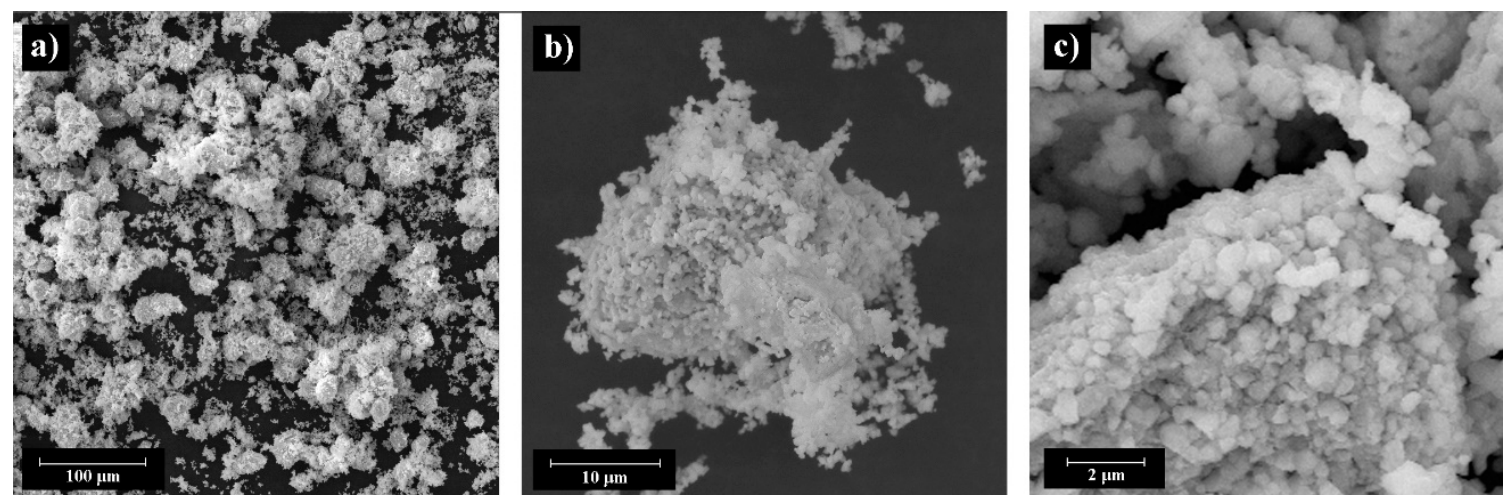

Figure 1. SEM images of $\mathrm{C}-\mathrm{BaTiO}_{3}$ powder at different magnifications: general view (a), agglomerate (b), powder particles (c).
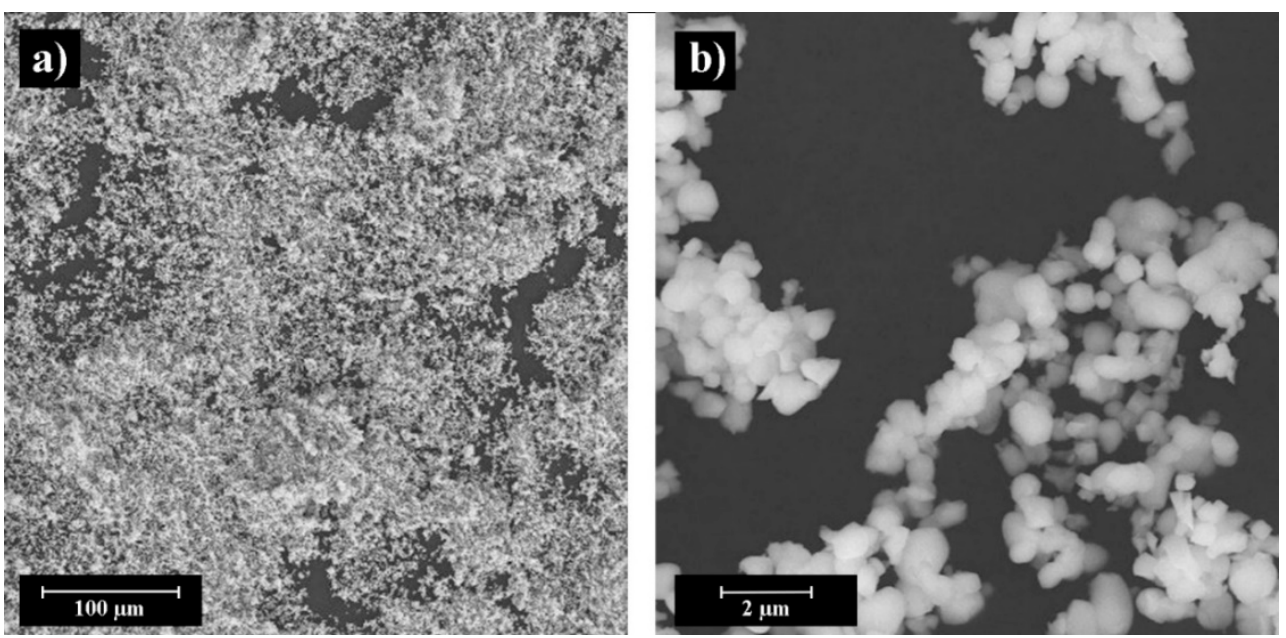

Figure 2. SEM images of $\mathrm{F}^{-\mathrm{BaTiO}_{3}}$ powder at different magnifications: general view (a), powder particles (b).

a)

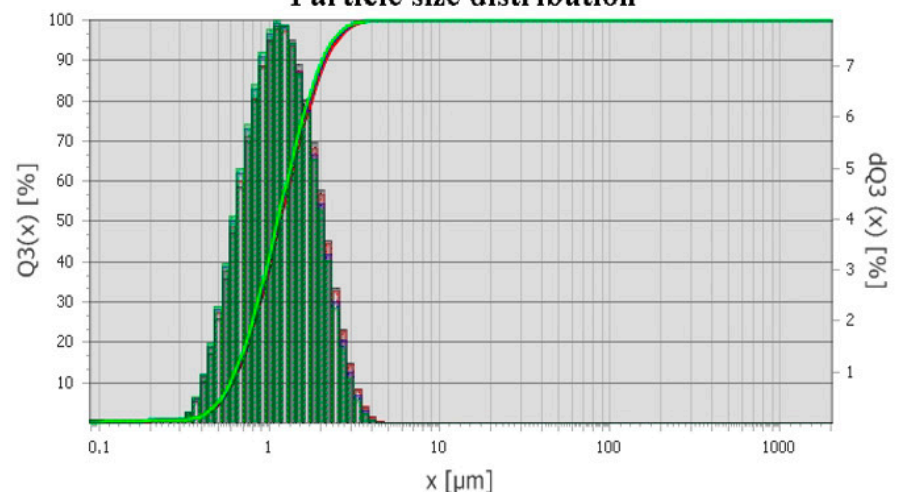

b)

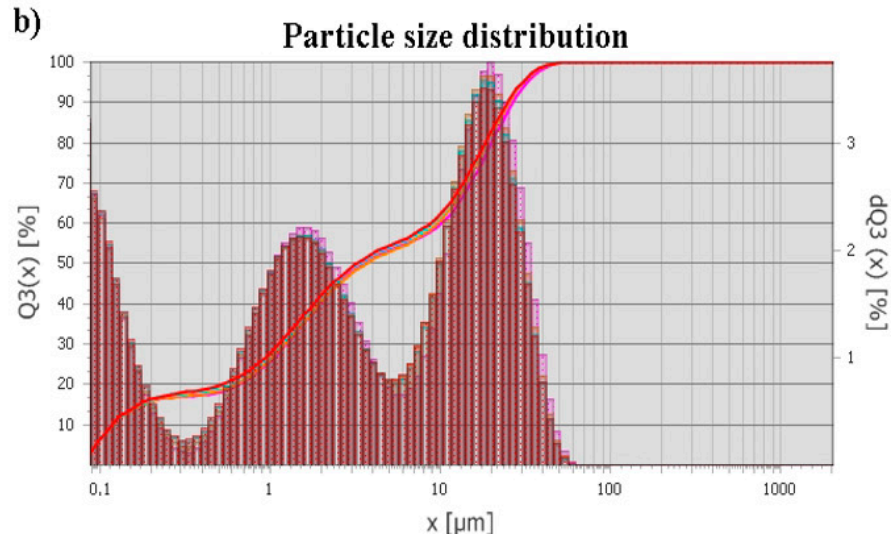

Figure 3. Particle size distribution of $\mathrm{F}-\mathrm{BaTiO}_{3}(\mathbf{a})$ and $\mathrm{C}-\mathrm{BaTiO}$ (b). 


\subsection{Fabrication}

For the experiment green models of cubic shape with dimensions of $10 \times 10 \times 10 \mathrm{~mm}^{3}$ were printed to study subsequent debinding and sintering processes. Also, the two types of cylindrical green models (diameter $15 \mathrm{~mm}$ and $10 \mathrm{~mm}$, height $10 \mathrm{~mm}$ and $1 \mathrm{~mm}$ respectively) were printed to investigate the electromechanical properties.

The piezoceramic samples were manufactured on the ExOne Innovent system (The ExOne Company, North Huntingdon, PA, USA). This system relates to the BJ additive manufacturing process. The original ExOne BS004 solvent binder and CL001 cleaner were used for the printing of the functional ceramic components.

The BJ process can be divided into several stages, a schematic image of which is shown in Figure 4:

1. A thin layer of powder material is formed on the platform using a roller;

2. A liquid binder is selectively sprayed to the powder layer using a print head, in accordance with the cross-section of the computer model;

3. Then the platform is lowered to a given thickness of one layer;

4. The powder layer is dried and heated using an infrared heater;

5. From the hopper, using an oscillator, the powder is fed to the surface of the platform and a new layer of powder is applied;

6. Then the layer is leveled using a rotating roller;

7. Processes 1-6 are repeated until a full-size green model is made.

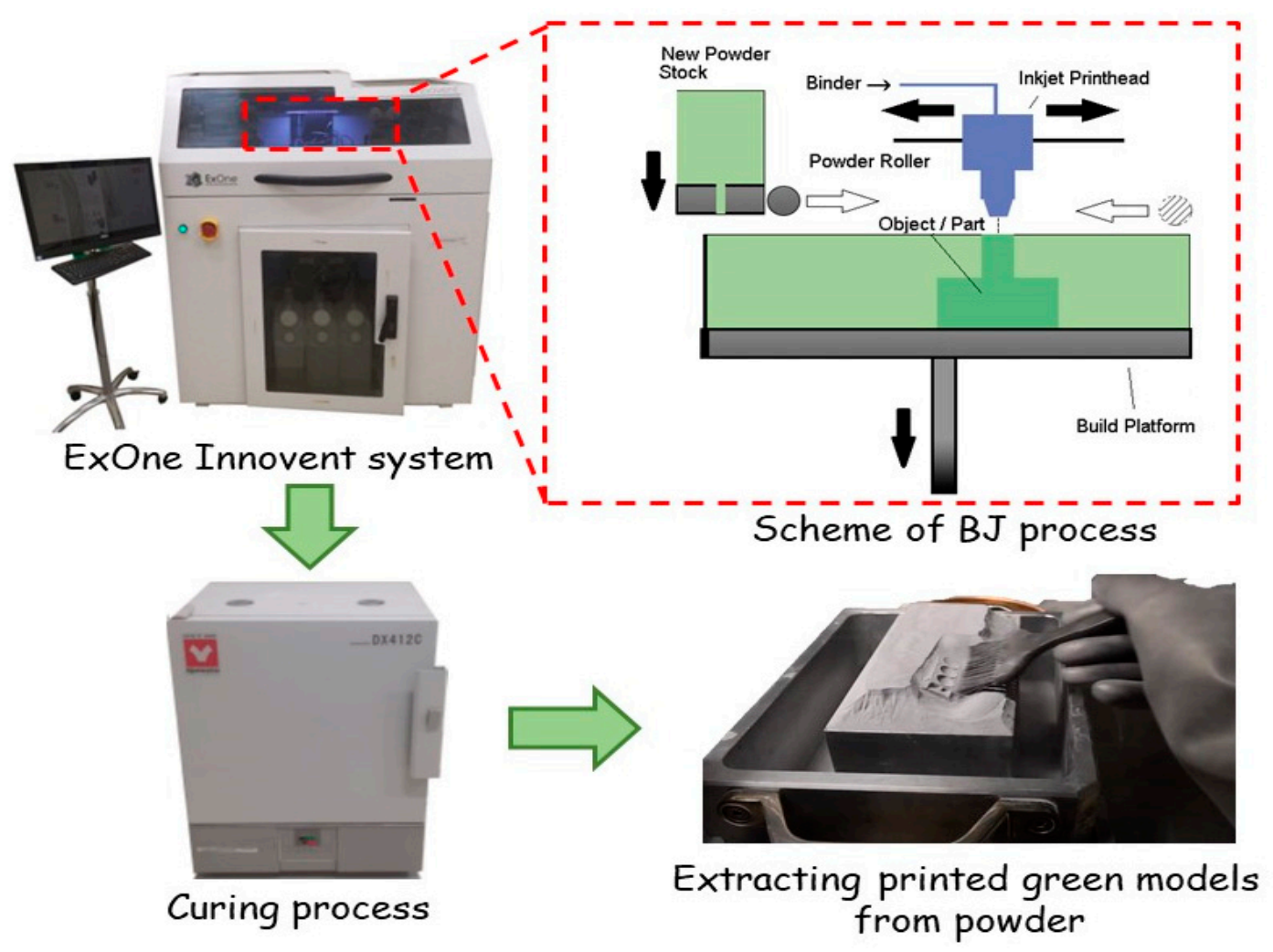

Figure 4. Process flow for BJ additive manufacturing.

Printed parts are considered "green" and are not suitable for end-use. Thus, these green models require further post-processing, such as sintering or infiltration, to achieve the desired mechanical and functional properties.

After the 3D printing, the platform (together with the green models in the powder surround) is placed in the thermal furnace (Yamato DX412C, Yamato Scientific, Santa Clara, CA, USA) at $180^{\circ} \mathrm{C}$ for $3 \mathrm{~h}$ for curing. 
After curing, the green models have sufficient strength to remove excess and loose powder. For green models of a simple shape, removal was done with a brush; for complex shapes removal was done using compressed air.

\subsection{Thermal Post-Treatment}

Before thermal post-treatment, the green models were placed in alumina crucibles with lids. The debinding process was performed in a muffle furnace (KJ-1700X, Zhengzhou Kejia Furnace Co., Ltd., Zhengzhou, China) at a temperature of $650{ }^{\circ} \mathrm{C}$ with a dwell time of $60 \mathrm{~min}$. After debinding, the samples were sintered in a muffle furnace at 1300, 1350, and $1400{ }^{\circ} \mathrm{C}$ with a dwell times of 2,4 , and $6 \mathrm{~h}$ under an air atmosphere. The thermal post-treatment profiles are illustrated in Figure 5.

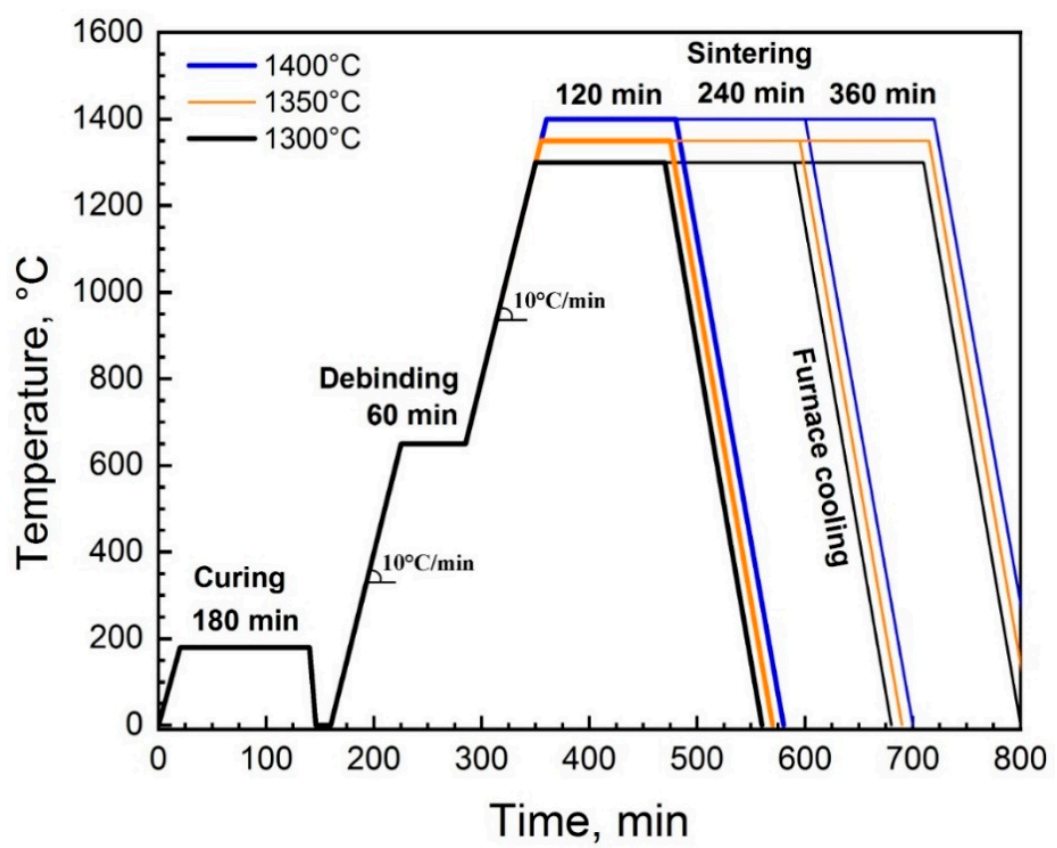

Figure 5. The thermal post-treatment profile.

\subsection{Characterization}

The particle size distribution of the powders was determined by laser diffraction Analysette 22 NanoTec plus (Fritsch, Idar-Oberstein, Germany) with a total measurement range of $0.01-2000 \mu \mathrm{m}$.

TGA analysis of BS004 solvent binder was performed using a thermogravimetric analyzer (Q5000, TA Instruments, New Castle, DE, USA). The heating was carried out in an airflow of $30 \mathrm{~mL} / \mathrm{min}$ in the temperature range $30-700{ }^{\circ} \mathrm{C}$ at a rate of $10^{\circ} \mathrm{C} / \mathrm{min}$. The binder was placed in a platinum crucible, after which it was heated from room temperature up to $700{ }^{\circ} \mathrm{C}$ in air.

The structure of the samples after sintering was studied using a Leica DMI5000 optical microscope (Leica, Wetzlar, Germany) and a Tescan Mira3 LMU scanning electron microscope (SEM) operating at magnifications from $4 \times$ to $10^{6} \times$ with an accelerating voltage from $200 \mathrm{~V}$ to $30 \mathrm{kV}$. The chemical composition was measured using an energy-dispersion accessory into the SEM.

Optical and SEM-images of sintered samples from C-BaTiO ${ }_{3}$ and $\mathrm{F}_{-}-\mathrm{BaTiO}_{3}$ were examined using the ImageJ Software. v.1.52a (Bethesda, MD, USA) The grain sizes were analyzed for various temperature and time sintering conditions.

The density of the sintered samples was measured by the Archimedes method; the calculation of relative density was made in accordance with the theoretical density of $\mathrm{BaTiO}_{3}\left(6.02 \mathrm{~g} / \mathrm{cm}^{3}\right)$. 
The phase composition was analyzed using a Bruker D8 Advance X-ray (Bruker corp., Billerica, MA, USA) diffractometer (XRD) using CuKa radiation ( $1=1.5418 \AA$ ) without monochromator.

All samples for the electrical performance test were coated with silver electrodes (paste PP-17, Delta, Zelenograd, Russia) at $700{ }^{\circ} \mathrm{C}$ for $30 \mathrm{~min}$. The samples were poled in air, at $\mathrm{Tc}+20{ }^{\circ} \mathrm{C}$ (Tc-Curie temperature $120-130{ }^{\circ} \mathrm{C}$ for $\mathrm{BaTiO}_{3}$ ). Then, an electric field of $0.6 \mathrm{kV} / \mathrm{mm}$ for $30 \mathrm{~min}$ was applied to samples, followed by cooling to room temperature. Dielectric constant $\varepsilon$, the loss tangent $\operatorname{tg} \delta$, electromechanical coupling coefficient $\mathrm{k}_{\mathrm{p}}$, and piezoelectric coefficient $\mathrm{d}_{33}$ were measured and calculated. Dielectric properties were measured on cylindrical samples with a diameter of $10 \mathrm{~mm}$ and a height of $1 \mathrm{~mm}$. The capacity of the sample and the loss tangent were measured with an E7-28 immittance analyzer at $1 \mathrm{kHz}$ frequency at $0.5 \mathrm{~V}$ effective voltage. The piezoelectric coefficient $\mathrm{d}_{33}$ was determined on polarized cylindrical samples using the APC YE2730A setup by a quasistatic method. The values of the electromechanical coupling coefficient were calculated by the following equation:

$$
\mathrm{k}_{\mathrm{p}}=\sqrt{\frac{\delta_{\mathrm{p}}}{\mathrm{a}_{\mathrm{p}}+\mathrm{b}_{\mathrm{p}} \cdot \delta_{\mathrm{p}}}},
$$

where, $a_{p}, b_{p}$ are the coefficients determined of Planar Poisson's Ratio, $\delta_{p}$ is the relative resonance gap. The Planar Poisson's ratio value was determined by the frequencies ratio of the third and first (main) overtones of the planar vibration mode on piezoelectric elements in the form of a disk.

\section{Results and Discussion}

\subsection{Investigation of Debinding Process}

The TGA curve showed that when heated to $180.5^{\circ} \mathrm{C}$ a sharp mass decrease by $86.82 \%$ was observed (Figure 6). This is due to the evaporation of two components: ethylene glycol monobutyl ether (EGBE), isopropanol (IPA), and the polymerization of ethylene glycol to polyethylene glycol. The boiling temperatures of evaporating components are much lower at $171^{\circ} \mathrm{C}$ and $80.4^{\circ} \mathrm{C}$, respectively.

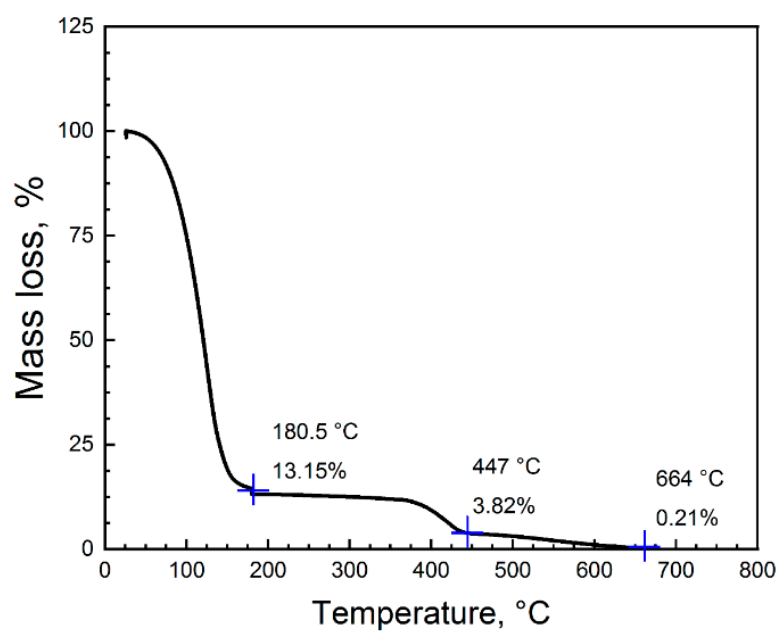

Figure 6. TGA analysis of the binder.

A further mass decrease occurred at a temperature range of $380-450{ }^{\circ} \mathrm{C}$. As a result, the remaining mass of the binder was $0.82 \%$ of the initial one. Increasing the temperature leads to a linear decreasing of mass; the binder was almost completely thermally decomposed at $664{ }^{\circ} \mathrm{C}$ and the residue was $0.21 \%$ of the initial mass. Thus, mass loss of the binder is observed in two stages: the first stage-mass decreases on $86.85 \%$, this stage ends at a temperature of $180.5^{\circ} \mathrm{C}$. The second stage is the temperature range from 180 to $664{ }^{\circ} \mathrm{C}$. 
Here, from 180 to $447^{\circ} \mathrm{C}$, no significant mass loss occurs. From 447 to $664^{\circ} \mathrm{C}$, the mass loss is up to $0.21 \%$ of the original mass.

The first stage is associated with the transition of ethylene glycol to polyethylene glycol during curing, the second stage is debinding by the burn out of the residue components of the binder [40].

\subsection{Binder Jetting Process}

For the BJ process, the recoating speed $\left(28 \mathrm{~mm} / \mathrm{s}\right.$ and $65 \mathrm{~mm} / \mathrm{s}$ for $\mathrm{C}-\mathrm{BaTiO}_{3}$ and $\mathrm{F}_{-} \mathrm{BaTiO}_{3}$ respectively) and the frequency of the oscillator (5000 rpm and $4400 \mathrm{rpm}$ for C$\mathrm{BaTiO}_{3}$ and $\mathrm{F}-\mathrm{BaTiO}_{3}$ respectively) were previously optimized to apply a sufficient amount of material to form a smooth thin powder layer. Considering this, the layer thickness for C-BaTiO 3 and $\mathrm{F}_{-}-\mathrm{BaTiO}_{3}$ powder was $100 \mu \mathrm{m}$ and $35 \mu \mathrm{m}$, respectively. The drying time and temperature were also optimized to achieve a uniform layer without cracking and without smearing. The main BJ parameters are shown in Table 1.

Table 1. The main $\mathrm{BJ}$ parameters for $\mathrm{BaTiO}_{3}$ lead-free piezoceramic powder.

\begin{tabular}{ccc}
\hline Process Parameter & C-BaTiO $_{3}$ Powder & F-BaTiO $_{3}$ Powder $^{-B}$ \\
Recoating speed & $28 \mathrm{~mm} / \mathrm{s}$ & $65 \mathrm{~mm} / \mathrm{s}$ \\
Frequency of the oscillator & $5000 \mathrm{rpm}$ & $4400 \mathrm{rpm}$ \\
Layer thickness & $100 \mu \mathrm{m}$ & $35 \mu \mathrm{m}$ \\
Drying time & $25 \mathrm{~s}$ & $20 \mathrm{~s}$ \\
Drying temperature & $25{ }^{\circ} \mathrm{C}$ & $33{ }^{\circ} \mathrm{C}$ \\
Roller movement speed & $1 \mathrm{~mm} / \mathrm{s}$ & $1 \mathrm{~mm} / \mathrm{s}$ \\
\hline
\end{tabular}

Further, the saturation parameter was investigated. Binder saturation is a computed value used to quantify how much binder is dispensed into each unit volume of powder material. Improper saturation of the binder can cause an inhomogeneous layer of powder as well as inaccurate dimensions of printed parts. The theoretical binder saturation (\%) was estimated using the following equation:

$$
S=\frac{1000 \times V}{\left(1-\left(\frac{P R}{100}\right)\right) \times X \times Y \times Z^{\prime}}
$$

where $\mathrm{V}$ is the volume of binder per drop $(\mathrm{pL}), \mathrm{PR}$ is the packing rate $(\%), \mathrm{X}$ and $\mathrm{Y}$ are the spacing between binder droplets $(\mu \mathrm{m})$, and $\mathrm{Z}$ is the layer thickness $(\mu \mathrm{m})$. To obtain the green part with sufficient mechanical strength and surface quality, optimizing the saturation level is critical.

The saturation for $\mathrm{C}-\mathrm{BaTiO}_{3}$ powder varied from 40 to $140 \%$ with a step of $20 \%$. For $\mathrm{F}-\mathrm{BaTiO}_{3}$ powder, the saturation varied from 50 to $200 \%$ with a step of $50 \%$. When printing the $\mathrm{C}-\mathrm{BaTiO}_{3}$ and $\mathrm{F}-\mathrm{BaTiO}_{3}$ samples, no defects were observed on the surface of the powder layer. The powder layer was applied uniformly, the particles did not stick to the roller. After curing of $\mathrm{C}-\mathrm{BaTiO}_{3}$ samples printed at $40 \%$ saturation, the green model delaminated. At $60 \%$ and $80 \%$ saturation, the deviation from the computer model size amounted to $0.37 \mathrm{~mm}$ along the $X$ and $Y$-axes and more than $0.1 \mathrm{~mm}$ along the Z-axis. For $100 \%$ saturation, the $\mathrm{C}-\mathrm{BaTiO}_{3}$ samples had clear boundaries and the deviation from the computer model size was about $0.2 \mathrm{~mm}$ along the $\mathrm{X}$ and $\mathrm{Y}$-axes, and less than $0.05 \mathrm{~mm}$ along the Z-axis. At $120 \%$ and $140 \%$ saturation, the geometry of the green models changed significantly and appeared to be barrel-shaped.

After curing of $\mathrm{F}_{-} \mathrm{BaTiO}_{3}$ samples printed at 50\% saturation, the green model delaminated since there was not enough binder to bond the layers together. For $100 \%$ saturation, the $\mathrm{F}_{-} \mathrm{BaTiO}_{3}$ samples had clear boundaries and the deviation from the computer model size was about $0.2 \mathrm{~mm}$ along the $X$ and $Y$-axes, and less than $0.02 \mathrm{~mm}$ along the Z-axis. At $150 \%$ and $200 \%$ saturation, the deviation from the computer model size amounted to 
$0.36 \mathrm{~mm}$ and $0.38 \mathrm{~mm}$ along the $X$ and $Y$-axes and more than $0.21 \mathrm{~mm}$ and 0.25 along the Z-axis, respectively.

\subsection{Investigation of Sintering Process, Shrinkage, Microstructure, Porosity}

For investigation of sintering process $\mathrm{BaTiO}_{3}$ samples, the following samples were selected: $\mathrm{C}-\mathrm{BaTiO}_{3}$ samples printed at 60,80 , and $100 \%$ saturation; $\mathrm{F}-\mathrm{BaTiO}_{3}$ samples printed at 100,150 , and $200 \%$ saturation.

To understand the influence of saturation level test-sintering was carried out at $1400{ }^{\circ} \mathrm{C}$ with a dwell time of $4 \mathrm{~h}$. Samples of $\mathrm{C}-\mathrm{BaTiO}_{3}$ printed with 60 and $80 \%$ saturation after test-sintering delaminated due to the weak contact between the layers. Also, $\mathrm{F}-\mathrm{BaTiO}_{3}$ samples cracked at 150 and $200 \%$ saturation, which is due to the high content of the binder. Seemingly, due to the high content of the binder in samples, during debinding and subsequent sintering, the formation of a large amount of gas occurred, leading to the appearance of cracks. However, the $\mathrm{C}-\mathrm{BaTiO}_{3}$ and $\mathrm{F}-\mathrm{BaTiO}_{3}$ samples printed at $100 \%$ saturation after test-sintering were free from defects. Figure 7 shows an image of $\mathrm{F}-\mathrm{BaTiO}_{3}$ samples obtained at different saturations after test-sintering. As a result, samples with $100 \%$ saturation for both types of powder were selected for further investigation of the sintering process.
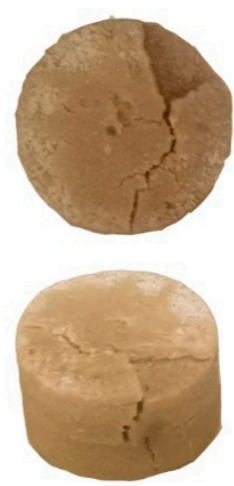

Saturation $200 \%$
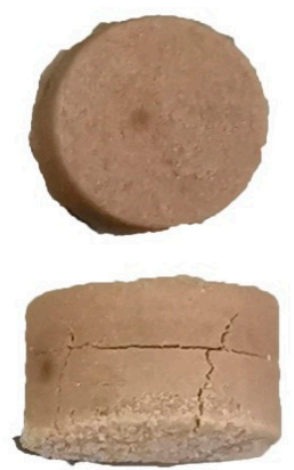

Saturation $150 \%$
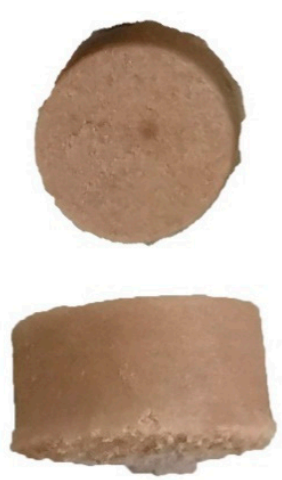

Saturation $100 \%$

Figure 7. Images of $\mathrm{F}^{-\mathrm{BaTiO}_{3}}$ samples printed by BJ with different saturation after sintering. Scale: each sample has a diameter of $15 \mathrm{~mm}$ and a height of $10 \mathrm{~mm}$. Heating rate of $10^{\circ} \mathrm{C} / \mathrm{min}$ to $1400{ }^{\circ} \mathrm{C}$ with a dwell time of $4 \mathrm{~h}$.

Subsequently, these samples were subjected to sintering in the temperature range of 1300-1400 ${ }^{\circ} \mathrm{C}$ for $2-6 \mathrm{~h}$. Sintering experiments at temperature $1500{ }^{\circ} \mathrm{C}$ led to the melting of $\mathrm{BaTiO}_{3}$ and the destruction of the samples. Initially, the study of the sintering process was carried out for $\mathrm{C}-\mathrm{BaTiO}_{3}$ samples at various temperatures of 1300,1350 , and $1400{ }^{\circ} \mathrm{C}$. The best value for the density of the material was achieved at $1400{ }^{\circ} \mathrm{C}$. Considering that the particle size of the $\mathrm{C}-\mathrm{BaTiO}_{3}$ powder is close to the particle size of the $\mathrm{F}-\mathrm{BaTiO}$ - powder (but different agglomerates sizes), a further investigation of sintering for the $\mathrm{F}-\mathrm{BaTiO}_{3}$ samples was carried out at a temperature of $1400{ }^{\circ} \mathrm{C}$ with dwell times of 2,4 , and $6 \mathrm{~h}$.

Figure 8 shows graphs of the dependence of sintered samples density on dwell time. The density of the samples increases with an increasing dwell time. The density of $\mathrm{F}-\mathrm{BaTiO}_{3}$ samples is higher compared to $\mathrm{C}-\mathrm{BaTiO}_{3}$ samples. The density of $\mathrm{C}-\mathrm{BaTiO}_{3}$ samples is lower, but the printing speed is higher due to layer thickness difference. During the printing of cylindrical samples from $\mathrm{F}_{-}-\mathrm{BaTiO}_{3}$ with $15 \mathrm{~mm}$ diameter and $10 \mathrm{~mm}$ height, the printing time was $7 \mathrm{~h}$, which is $4 \mathrm{~h}$ longer than the printing time for similar size samples from $\mathrm{C}-\mathrm{BaTiO}_{3}$ powder. 


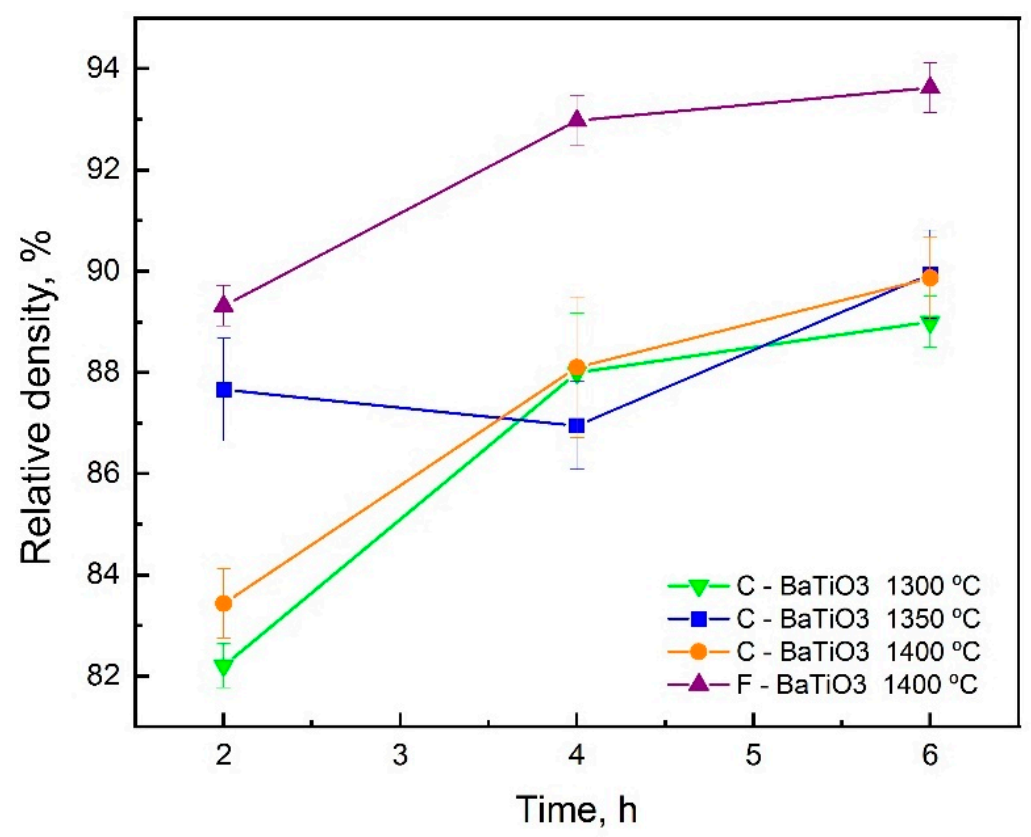

Figure 8. Dependence of the density of samples on temperature and dwell time of sintering.

Increasing the temperature and dwell time of sintering leads to grain enlargement. The graphs in Figure 9 show that the grain size of samples from the unimodal powder is more sensitive to changes in temperature and dwell time compared to samples made from multimodal powder. This feature allows adjusting the functional properties of the material in a wider range.

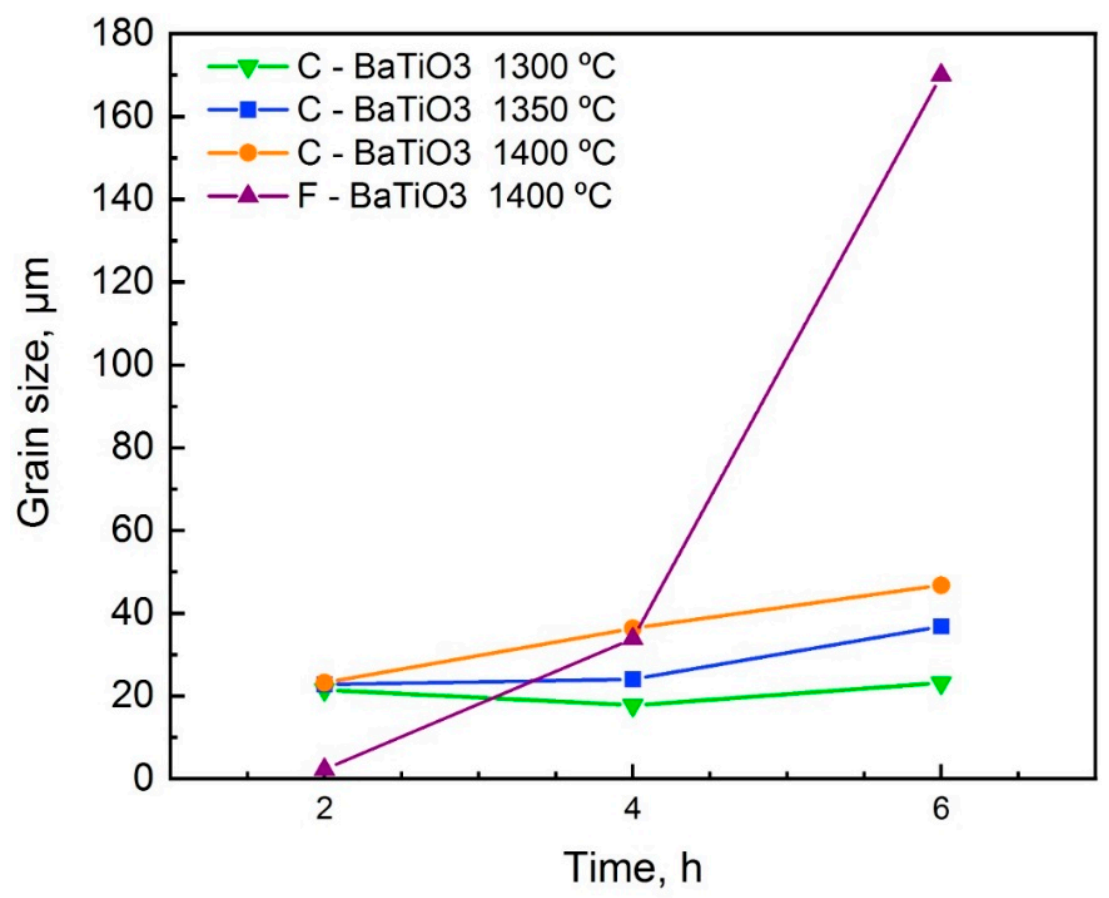

Figure 9. Grain size of $\mathrm{BaTiO}_{3}$ samples dependence on temperature and dwell time of sintering.

As a result of the sintering of samples from $\mathrm{C}-\mathrm{BaTiO}_{3}$, the shrinkage along the $\mathrm{XY}$ direction was $20-25 \%$. The Z-axis shrinkage varied from $24.1 \%$ to $24.4 \%$. The measured linear shrinkage of samples from $\mathrm{F}_{-}-\mathrm{BaTiO}_{3}$ along the XY direction was $24-27 \%$. The Z-axis shrinkage was $25-26 \%$. 
The microstructure of the sintered $\mathrm{BaTiO}_{3}$ samples is shown in Figure 10. The structure is a rounded grain formed as a result of sintering the powder material. Some sintered samples have round-shaped pores, these defects may be associated with binder removal since at this stage there is active gas formation, and perhaps a consequence of the nonoptimal sintering mode as well.
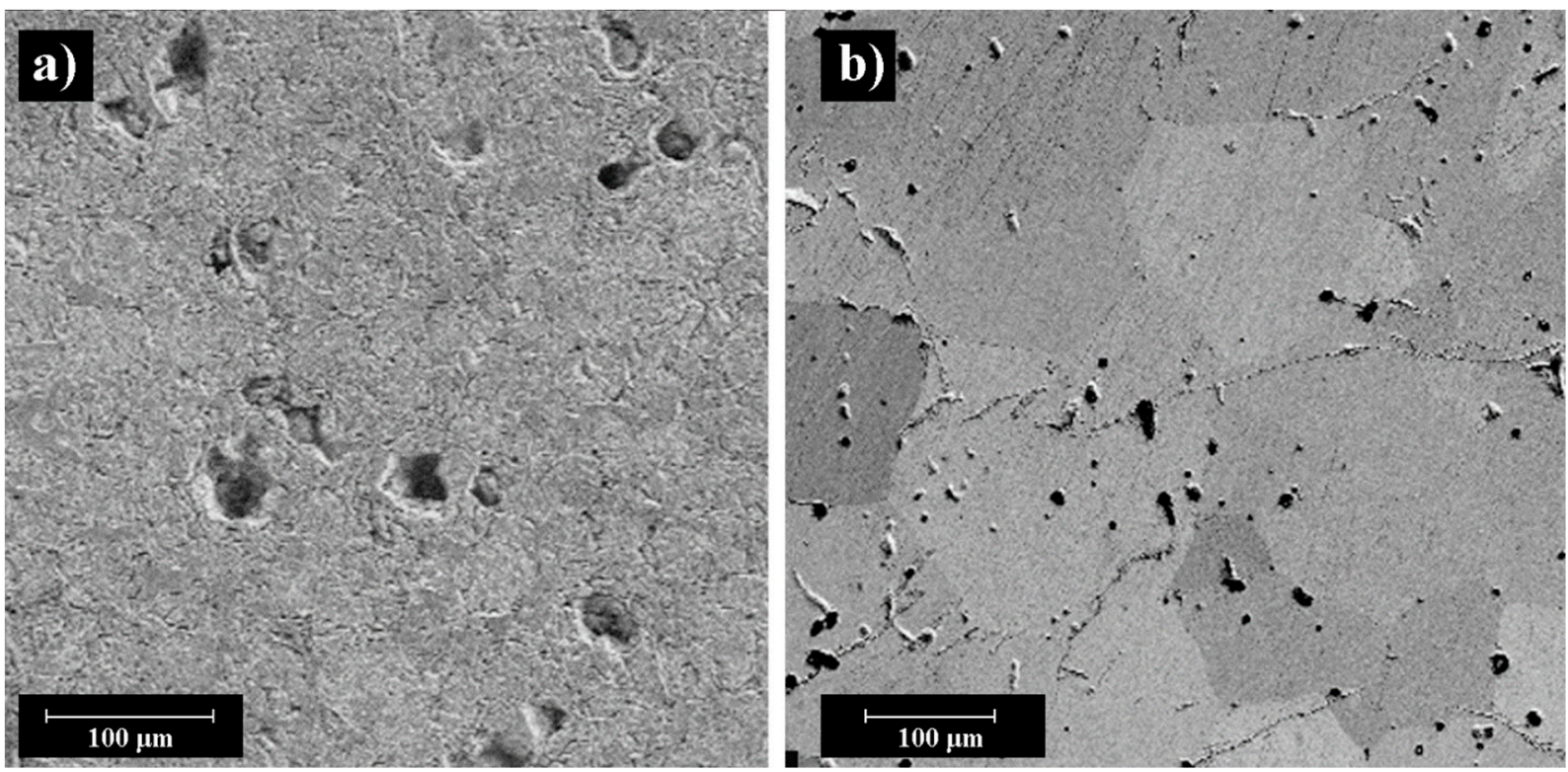

Figure 10. SEM images of sintered samples microstructures at $1400{ }^{\circ} \mathrm{C}$, a dwell time of $6 \mathrm{~h}$ from C-BaTiO${ }_{3}(\mathbf{a})$ and $\mathrm{F}-\mathrm{BaTiO}_{3}$ (b) powders.

According to EDS measurements, the chemical composition of samples was 59.2\% of $\mathrm{Ba}, 18.8 \%$ of $\mathrm{Ti}$, and $22 \%$ of $\mathrm{O}$ (weight $\%$ ) which corresponds with $\mathrm{BaTiO}_{3}$ formulation. Figure 11 shows the diffraction patterns of the $\mathrm{C}-\mathrm{BaTiO}_{3}$ samples. X-ray diffraction analysis showed that all samples are composed of the tetragonal crystal lattice $\mathrm{P}_{4} \mathrm{~mm}$ of $\mathrm{BaTiO}_{3}$, as evidenced by bifurcated peaks (compare to cubic lattice Pm-3m).

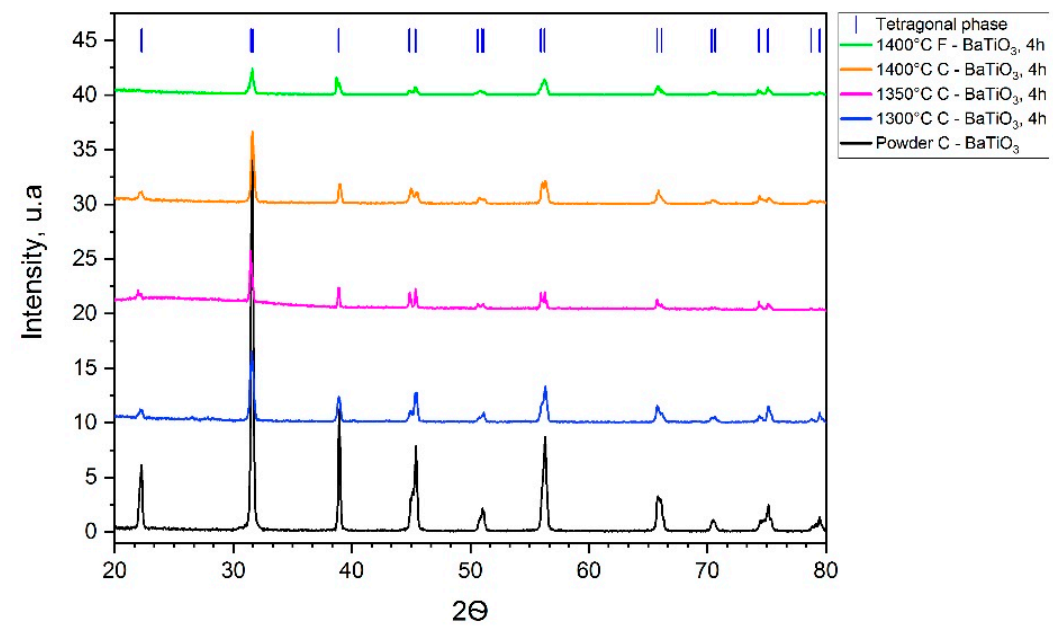

Figure 11. XRD of a sample sintered at different temperatures.

To demonstrate the applicability of the developed modes of the BJ process and thermal post-treatment for manufacturing parts with complex geometries, test samples with lattice structures were made from $\mathrm{F}_{-}-\mathrm{BaTiO}_{3}$ powder (Figure 12). 


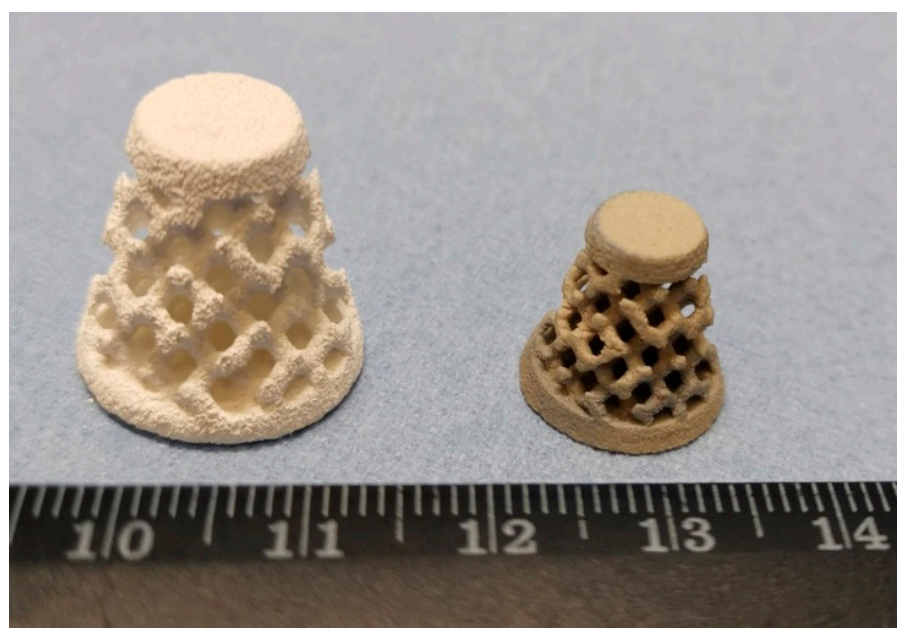

Figure 12. Image of samples with lattice structures printing by $\mathrm{BJ}$ from $\mathrm{F}_{-}-\mathrm{BaTiO}_{3}$ powder before (left) and after sintering (right).

\subsection{Investigation of Functional Properties}

The investigation of the functional piezoelectric properties was carried out for C$\mathrm{BaTiO}_{3}$ samples (a temperature of $1400{ }^{\circ} \mathrm{C}$ and a dwell time of $6 \mathrm{~h}$ ) and $\mathrm{F}^{-\mathrm{BaTiO}_{3}}$ (a temperature of $1400{ }^{\circ} \mathrm{C}$ and a dwell time of $4 \mathrm{~h}$ ). These samples were selected considering the highest density and grain size up to 50 microns. This grain size is due to the fact that, for $\mathrm{BaTiO}_{3}$-based piezoceramic, the high functional properties arise with a grain size of 10 to $50 \mu \mathrm{m}$ [41]. Table 2 shows the test results of the functional properties of sintered samples manufactured from multimodal and unimodal $\mathrm{BaTiO}_{3}$ powders. Samples printed from $\mathrm{C}-\mathrm{BaTiO}_{3}$ powder are inferior in dielectric constant, electromechanical coupling coefficient, and piezoelectric coefficient to samples printed from $\mathrm{F}_{-} \mathrm{BaTiO}_{3}$. This can be explained by the non-optimal mode of debinding and sintering, the presence of large pores, and as a result, a decrease of the active phase volume of the sample.

Table 2. Piezoelectric properties at $1 \mathrm{kHz}$ of $\mathrm{BaTiO}_{3}$ samples printed by $\mathrm{BJ}$ process.

\begin{tabular}{|c|c|c|c|c|}
\hline Technology/Powder Type & $\dot{\varepsilon}$ & $\operatorname{tg} \delta, \%$ & $\mathbf{k}_{\mathbf{p}}$ & $\mathrm{d}_{33}, \mathrm{pC} / \mathrm{N}$ \\
\hline Binder Jetting/C-BaTiO 3 & 750 & 5.53 & 0.15 & 118 \\
\hline Traditional technology/C-BaTiO 3 & 1872 & 7.9 & 0.22 & 163 \\
\hline Binder Jetting $/ \mathrm{F}-\mathrm{BaTiO}_{3}$ & 811 & 11.59 & 0.19 & 183 \\
\hline Traditional technology/F-BaTiO 3 & 2367 & 1.7 & 0.36 & 230 \\
\hline
\end{tabular}

Appreciating the main parameter piezoelectric coefficient $\mathrm{d}_{33}$, it can be noted that using the BJ process allows achieving $72.4 \%$ of the piezoelectric coefficient compared to the value obtained by traditional manufacturing technology with multimodal PSD powder and $79.6 \%$ of the $d_{33}$ values obtained with unimodal PSD powder. Pressing and sintering were used as the traditional technology, and a solution of polyvinyl alcohol was used as a binder. Sintering was carried out at a temperature of $1350^{\circ} \mathrm{C}$, heating rate $100{ }^{\circ} \mathrm{C} / \mathrm{h}$, a dwell time of $3 \mathrm{~h}$.

According to the results of studies published in [32], the functional characteristics of $\mathrm{AM}$ piezoceramics depend on the direction of measurement. The functional properties along the Z-axis are about $20 \%$ smaller in comparison with the XY direction. In the current study, the properties were measured only along the Z-axis, but the achieved values of piezoelectric coefficient $d_{33}=183 \mathrm{pC} / \mathrm{N}$ and dielectric constant $\dot{\varepsilon}=811$ exceed the values obtained by the authors [32] parallel $\left(\mathrm{d}_{33}=113 \mathrm{pC} / \mathrm{N}, \hat{\varepsilon}=581.6\right)$ and perpendicular to the printing orientation $\left(\mathrm{d}_{33}=152.7 \mathrm{pC} / \mathrm{N}, \varepsilon=698\right)$. These differences seem to be related to the raw material and the corresponding difference in technological parameters of $\mathrm{BJ}$ and subsequent thermal post-treatment. 
The presented results demonstrate that the use of a unimodal PSD powder of lead-free piezoceramics barium titanate allows achieving higher piezoelectric properties, and the use of binder jetting technology allows the creation of objects with complex geometry, which has potential in the manufacture of ultrasonic products used in medicine, aviation, marine industry, sensors for monitoring welded joints, pressure sensors in pipelines, etc.

Future research areas that allow for improving piezoelectric properties include the use of new lead-free piezoelectric materials with increased characteristics (such as KNN, BZT$\mathrm{BCT}$, etc.), as well as the creation of functional gradient systems and the use of multimaterial $3 \mathrm{D}$ printing.

\section{Conclusions}

The paper presents the results of the additive manufacturing of piezoelectric elements using the binder jetting process. Two powders with different particle size distributions were used as raw materials. Binder jetting with $100 \%$ saturation for $\mathrm{C}-\mathrm{BaTiO}_{3}$ and for $\mathrm{F}^{-\mathrm{BaTiO}_{3}}$ allows printing samples without delamination and cracking. Sintering at $1400{ }^{\circ} \mathrm{C}$ with a dwell time of $6 \mathrm{~h}$ forms the highest density samples. It was determined that samples from the unimodal powder are more sensitive to increasing grain size during sintering. The measured dielectric and piezoelectric properties of the samples also demonstrated that samples from unimodal powder $\mathrm{F}_{-} \mathrm{BaTiO}_{3}$ have higher values. The results of the functional piezoelectric properties obtained by binder jetting with $\mathrm{C}-\mathrm{BaTiO}_{3}$ are $\mathrm{d}_{33}=118 \mathrm{pC} / \mathrm{N}$, $\dot{\varepsilon}=750$, and with $\mathrm{F}-\mathrm{BaTiO}_{3}: \mathrm{d}_{33}=183 \mathrm{pC} / \mathrm{N}, \dot{\varepsilon}=811$.

The future possibilities of improving functional characteristics of samples manufactured with BJ are increasing speed, optimizing sintering modes, and using new lead-free piezoelectric materials with improved functional characteristics.

Author Contributions: Conceptualization, V.S.; investigation, A.K. and V.S.; methodology, A.S.; project administration, V.S. and A.P.; funding acquisition, A.P.; writing—original draft, A.K. and A.S.; writing - review \& editing, A.S. All authors have read and agreed to the published version of the manuscript.

Funding: The research was carried out as part of the work under the State Contract No. H.4щ.241.09. 20.1081 dated 04.06.2020 (ISC 17706413348200001110).

Institutional Review Board Statement: Not applicable.

Informed Consent Statement: Not applicable.

Data Availability Statement: The data presented in this study are available on request from the corresponding author.

Conflicts of Interest: The authors declare no conflict of interest.

\section{References}

1. Yin, Q.; Zhu, B.; Zeng, H. Microstructure, Property and Processing of Functional Ceramics; Springer: Berlin/Heidelberg, Germany, 2010; ISBN 3642016944.

2. Mostafaei, A.; Elliott, A.M.; Barnes, J.E.; Cramer, C.L.; Nandwana, P.; Chmielus, M. Binder jet 3D printing—Process parameters, materials, properties, and challenges. Prog. Mater. Sci. 2020, 100684. [CrossRef]

3. Eichel, R.-A.; Erünal, E.; Drahus, M.D.; Smyth, D.M.; van Tol, J.; Acker, J.; Kungl, H.; Hoffmann, M.J. Local variations in defect polarization and covalent bonding in ferroelectric $\mathrm{Cu}^{2+}$-doped PZT and $\mathrm{KNN}$ functional ceramics at the morphotropic phase boundary. Phys. Chem. Chem. Phys. 2009, 11, 8698-8705. [CrossRef]

4. Lin, X.; Yuan, F.G. Diagnostic Lamb waves in an integrated piezoelectric sensor/actuator plate: Analytical and experimental studies. Smart Mater. Struct. 2001, 10, 907. [CrossRef]

5. Chavez, L.A.; Jimenez, F.O.Z; Wilburn, B.R.; Delfin, L.C.; Kim, H.; Love, N.; Lin, Y. Characterization of thermal energy harvesting using pyroelectric ceramics at elevated temperatures. Energy Harvest. Syst. 2018, 5, 3-10. [CrossRef]

6. Zhao, X.; Gao, H.; Zhang, G.; Ayhan, B.; Yan, F.; Kwan, C.; Rose, J.L. Active health monitoring of an aircraft wing with embedded piezoelectric sensor/actuator network: I. Defect detection, localization and growth monitoring. Smart Mater. Struct. 2007, 16, 1208. [CrossRef]

7. Kim, H.; Torres, F.; Villagran, D.; Stewart, C.; Lin, Y.; Tseng, T.B. 3D printing of $\mathrm{BaTiO}_{3} / \mathrm{PVDF}$ composites with electric in situ poling for pressure sensor applications. Macromol. Mater. Eng. 2017, 302, 1700229. [CrossRef] 
8. Zhang, S.; Yu, F. Piezoelectric materials for high temperature sensors. J. Am. Ceram. Soc. 2011, 94, 3153-3170. [CrossRef]

9. Chavez, L.A.; Elicerio, V.F.; Regis, J.E.; Kim, H.; Rosales, C.A.G.; Love, N.D.; Lin, Y. Thermal and mechanical energy har-vesting using piezoelectric ceramics. Mater. Res. Express 2018, 6, 25701. [CrossRef]

10. Yonghong, L.; Zhixin, J.; Jinchun, L. Study on hole machining of non-conducting ceramics by gas-filled electrodischarge and electrochemical compound machining. J. Mater. Process. Technol. 1997, 69, 198-202. [CrossRef]

11. Cook, R.F.; Freiman, S.W.; Lawn, B.R.; Pohanka, R.C. Fracture of ferroelectric ceramics. Ferroelectrics 1983, 50, 267-272. [CrossRef]

12. Gao, W.; Zhang, Y.; Ramanujan, D.; Ramani, K.; Chen, Y.; Williams, C.B.; Wang, C.C.L.; Shin, Y.C.; Zhang, S.; Zavattieri, P.D. The status, challenges, and future of additive manufacturing in engineering. Comput. Des. 2015, 69, 65-89. [CrossRef]

13. Salehi, M.; Gupta, M.; Maleksaeedi, S.; Sharon, N.M.L. Inkjet Based 3D Additive Manufacturing of Metals; Materials Research Forum LLC: Millersville, PA, USA, 2018.

14. Xu, Y.; Wu, X.; Guo, X.; Kong, B.; Zhang, M.; Qian, X.; Mi, S.; Sun, W. The boom in 3D-printed sensor technology. Sensors 2017, 17, 1166. [CrossRef] [PubMed]

15. Zhang, X.; Song, S.; Yao, M.J. Fabrication of embedded piezoelectric sensors and its application in traffic engineering. In Proceedings of the 2017 2nd IEEE International Conference on Intelligent Transportation Engineering (ICITE), Singapore, 1-3 September 2017; pp. 259-265.

16. Bandyopadhyay, A.; Panda, R.K.; McNulty, T.F.; Mohammadi, F.; Danforth, S.C.; Safari, A. Piezoelectric ceramics and compo-sites via rapid prototyping techniques. Rapid Prototyp. J. 1998, 4, 37-49. [CrossRef]

17. Smay, J.E.; Cesarano, J.; Lewis, J.A. Colloidal inks for directed assembly of 3-D periodic structures. Langmuir 2002, 18, 5429-5437. [CrossRef]

18. Chen, Y.; Bao, X.; Wong, C.-M.; Cheng, J.; Wu, H.; Song, H.; Ji, X.; Wu, S. PZT ceramics fabricated based on stereolithography for an ultrasound transducer array application. Ceram. Int. 2018, 44, 22725-22730. [CrossRef]

19. Cui, H.; Hensleigh, R.; Yao, D.; Maurya, D.; Kumar, P.; Kang, M.G.; Priya, S.; Zheng, X.R. Three-dimensional printing of piezoelectric materials with designed anisotropy and directional response. Nat. Mater. 2019, 18, 234-241. [CrossRef]

20. Lejeune, M.; Chartier, T.; Dossou-Yovo, C.; Noguera, R. Ink-jet printing of ceramic micro-pillar arrays. J. Eur. Ceram. Soc. 2009, 29, 905-911. [CrossRef]

21. Wan, C.; Bowen, C.R. Multiscale-structuring of polyvinylidene fluoride for energy harvesting: The impact of molecular-, micro-and macro-structure. J. Mater. Chem. A 2017, 5, 3091-3128. [CrossRef]

22. Kim, H.; Renteria-Marquez, A.; Islam, M.D.; Chavez, L.A.; Garcia Rosales, C.A.; Ahsan, M.A. Fabrication of bulk piezoelectric and dielectric $\mathrm{BaTiO}_{3}$ ceramics using paste extrusion 3D printing technique. J. Am. Ceram. Soc. 2018, 102, 3685-3694. [CrossRef]

23. Nadkarni, S.S.; Smay, J.E. Concentrated Barium Titanate Colloidal Gels Prepared by Bridging Flocculation for Use in Solid Freeform Fabrication. J. Am. Ceram. Soc. 2005, 89, 96-103. [CrossRef]

24. Renteria, A.; Diaz, J.A.; He, B.; Renteria-Marquez, I.A.; Chavez, L.A.; Regis, J.E. Particle size influence on material properties of $\mathrm{BaTiO}_{3}$ ceramics fabricated using freeze-form extrusion 3D printing. Mater. Res. Express 2019, 6, 115211. [CrossRef]

25. Rowlands, W.; Vaidhyanathan, B. Additive manufacturing of barium titanate based ceramic heaters with positive temperature coefficient of resistance (PTCR). J. Eur. Ceram. Soc. 2019, 39, 3475-3483. [CrossRef]

26. Chen, Z.; Song, X.; Lei, L.; Chen, X.; Fei, C.; Chiu, C.T. 3D printing of piezoelectric element for energy focusing and ultrasonic sensing. Nano Energy 2016, 27, 78-86. [CrossRef]

27. Cheng, J.; Chen, Y.; Wu, J.-W.; Ji, Z.-R.; Wu, S.-H. 3D Printing of $\mathrm{BaTiO}_{3}$ Piezoelectric Ceramics for a Focused Ultrasonic Array. Sensors 2019, 19, 4078. [CrossRef]

28. Jang, J.H.; Wang, S.; Pilgrim, S.M.; Schulze, W.A. Preparation and characterization of barium titanate suspensions for stereolithography. J. Am. Ceram. Soc. 2000, 83, 1804-1806. [CrossRef]

29. Kim, K.; Zhu, W.; Qu, X.; Aaronson, C.; McCall, W.R.; Chen, S. 3D optical printing of piezoelectric nanoparticle-polymer composite materials. ACS Nano 2014, 8, 9799-9806. [CrossRef] [PubMed]

30. Sotov, A.; Kantyukov, A.; Popovich, A.; Sufiiarov, V. LCD-SLA 3D printing of $\mathrm{BaTiO}_{3}$ piezoelectric ceramics. Ceram Int. 2021. [CrossRef]

31. Gaytan, S.M.; Cadena, M.A.; Karim, H.; Delfin, D.; Lin, Y.; Espalin, D.; MacDonald, E.; Wicker, R.B. Fabrication of barium titanate by binder jetting additive manufacturing technology. Ceram Int. 2015, 41, 6610-6619. [CrossRef]

32. Chavez, L.A.; Wilburn, B.R.; Ibave, P.; Delfin, L.C.; Vargas, S.; Diaz, H.; Fulgentes, C.; Renteria, A.; Regis, J.; Liu, Y.; et al. Fabrication and characterization of 3D printing induced orthotropic functional ceramics. Smart Mater. Struct. 2019, $28,125007$. [CrossRef]

33. Chavez, L.A.; Ibave, P.; Wilburn, B.; Alexander, D.; Stewart, C.; Wicker, R.; Lin, Y. The influence of printing parameters, postprocessing, and testing conditions on the properties of binder jetting additive manufactured functional ceramics. Ceramics 2020, 3 , 65-77. [CrossRef]

34. Polley, C.; Distler, T.; Detsch, R.; Lund, H.; Springer, A.; Boccaccini, A.R.; Seitz, H. 3D printing of piezoelectric barium titanatehydroxyapatite scaffolds with interconnected porosity for bone tissue engineering. Materials 2020, 13, 1773. [CrossRef] [PubMed]

35. Chen, Z.; Yang, M.; Ji, M.; Kuang, X.; Qi, H.J.; Wang, T. Recyclable thermosetting polymers for digital light processing 3D printing. Mater. Des. 2021, 197, 109189. [CrossRef]

36. Sufiiarov, V.; Polozov, I.; Kantykov, A.; Khaidorov, A. Binder jetting additive manufacturing of 420 stainless steel: Densification during sintering and effect of heat treatment on microstructure and hardness. Mater. Today Proc. 2020, 30, 592-595. [CrossRef] 
37. Polozov, I.; Sufiiarov, V.; Shamshurin, A. Synthesis of titanium orthorhombic alloy using binder jetting additive manufacturing. Mater. Lett. 2019, 243, 88-91. [CrossRef]

38. Agapovichev, A.V.; Sotov, A.V.; Kokareva, V.V.; Smelov, V.G.; Kyarimov, R.R. Study of the structure and mechanical characteristics of samples obtained by selective laser melting technology from VT6 alloy metal powder. Nanosci. Technol. Int. J. 2017, 8, 323-330. [CrossRef]

39. Sufiiarov, V.; Kantyukov, A.; Polozov, I. Reaction sintering of metal-ceramic AlSI- $\mathrm{Al}_{2} \mathrm{O}_{3}$ composites manufactured by binder jetting additive manufacturing process. In Proceedings of the METAL 2020-29th International Conference on Metallurgy and Materials, Brno, Czech Republic, 20-22 May 2020; pp. 1148-1155. [CrossRef]

40. Do, T.; Kwon, P.; Shin, C.S. Process development toward full-density stainless steel parts with binder jetting printing. Int. J. Mach Tools Manuf. 2017, 121, 50-60. [CrossRef]

41. Acosta, M.; Novak, N.; Rojas, V.; Patel, S.; Vaish, R.; Koruza, J.; Rödel, J. BaTiO 3 -based piezoelectrics: Fundamentals, current status, and perspectives. Appl. Phys. Rev. 2017, 4, 041305. [CrossRef] 